\title{
EFFECTS OF PROBIOTIC SUPPLEMENTATION ON METABOLIC SYNDROME COMPONENTS IN TYPE 2 DIABETES MELLITUS PATIENTS - A CASE-CONTROL STUDY
}

\author{
Raluca A. CORB ARON ${ }^{1}$, Delia M. TIT ${ }^{1}$, Anamaria L. PURZA ${ }^{1}$, Areha ABID ${ }^{2}$, \\ Cosmin M. VESA ${ }^{1}$, Gabriela ANGELESCU ${ }^{3}$, Simona BUNGAU ${ }^{1}$. \\ ${ }^{1}$ Faculty of Medicine and Pharmacy, University of Oradea, Oradea, Romania \\ ${ }^{2}$ Faculty of Agricultural and Food Sciences, University of Debrecen, Debrecen, Hungary \\ 3 "Carol Davila" University of Medicine and Pharmacy, Internal Medicine Clinic, Clinical Emergency \\ Hospital of Ilfov County, Bucharest, Romania
}

Received 02 May 2021, Accepted 25 May 2021

https://doi.org/10.31688/ABMU.2021.56.2.09

\begin{abstract}
Introduction. Probiotics are well-known adjuvants, used as complementary therapeutic agents in health (e.g. metabolic or gastrointestinal) disorders, considering their beneficial role on gut microbiota, and their support in immunity.

The objective of the study. This research followed the impact of probiotic supplementation on some clinical parameters related to metabolic syndrome (MS) and type 2 diabetes mellitus (T2DM) (weight status, body mass index, carbohydrate/ lipid profiles).

Materials and methods. The comparative monitoring of the parameters was conducted over a 3-month period, on 41 subjects diagnosed with both MS and T2DM, who were separated into two groups, as follows: the study group (probiotics associated with allopathic treatment) and the control group (without probiotics).

Results. Administration of dietary probiotics had a major impact on body weight, weight loss being
\end{abstract}

\section{Résumé}

Effets de la supplémentation probiotique sur les composants du syndrome métabolique chez les patients avec diabète sucré de type 2 - une étude de contrôle de cas

Introduction. Les probiotiques sont des adjuvants connus, utilisés comme agents thérapeutiques complémentaires dans les déséquilibres de la santé (métaboliques ou gastro-intestinaux), compte tenu de leur rôle bénéfique sur le microbiote intestinal et de leur appui à l'immunité.

L'objectif de l'étude. Cette recherche a suivi l'impact de la supplémentation de probiotiques sur certains paramètres cliniques liés au syndrome métabolique (SM) et au diabète sucré de type 2 (T2DM) (statut pondéral, indice de masse corporelle, profils glucidiques/ lipidiques). Matériels et méthodes. Le suivi comparatif des paramètres a été réalisé sur une période de 3 mois, sur 
significantly enhanced in the probiotic group than in the diet-only group $(\mathrm{p}=0.01)$. The effect of dietary probiotic administration on glucidic and lipidic profile was small (effect size (ES) 0.26 and 0.33, respectively), but better than in the control group, in whom the evolution was insignificant (ES 0.10 and 0.10, respectively). From a statistical point of view, the differences were insignificant ( $p>0.05)$.

Conclusions. In the metabolic profile management of patients suffering from both MS and T2DM, probiotics administration had beneficial results, as highlighted by the results of the present study.

Keywords: metabolic syndrome, type 2 diabetes, weight status, glucidic profile, lipidic profile.

\section{List of abbreviations:}

BMI - body mass index

BP - blood pressure

CVD - cardiovascular disease

ES - effect size

HbAlc - glycosylated hemoglobin A1c

HDLc - high-density lipoprotein cholesterol

LDLc -low-density lipoprotein cholesterol

MS - metabolic syndrome

T2DM - type 2 diabetes

\section{INTRODUCTION}

The increasing prevalence of obesity is a wide-spread public health issue. Obesity enhances comorbidities, increasing mortality especially as result of cardiometabolic complications ${ }^{1}$. Specifically, the layer of visceral adipose tissue generates inflammatory cytokines that produce insulin resistance implicated in hypertension, type 2 diabetes mellitus (T2DM) and dyslipidemia, accentuating the risk of cardiovascular disease, the main cause of death ${ }^{2}$.

In this frame, T2DM represents also an important health issue world-wide, being the main risk factor for several ordinary diseases like coronary heart disease, hypertension, retinopathy, stroke and kidney failure ${ }^{3}$. Data from International Diabetes Federation (IDF) show a global DM rate of $8.8 \%$ in 2015 and a prediction of growth to $10.4 \%$ in adults by the year $2040^{4}$. Growing rates of obesity generates conditions for the increasing ratio of metabolic syndrome (MS) and $\mathrm{T}_{2} \mathrm{DM}^{5}$.

Insulin resistance and expended white adipose tissue are characteristics of MS, determining an increased risk of cardiovascular diseases (CVD) ${ }^{6}$. The IDF characterizes MS as resulting from central obesity together with two of the following factors: high-density lipoprotein cholesterol (HDLc) $<50 \mathrm{mg} / \mathrm{dL}$ in females, $<40 \mathrm{mg} / \mathrm{dL}$ in males or specific therapy for
41 sujets diagnostiqués à la fois avec SM et T2DM, qui ont été séparés en deux groupes, comme suit : le groupe d'étude (probiotiques associés au traitement allopathique) et le groupe témoin (sans probiotiques).

Résultats. L'administration de probiotiques alimentaires a eu un impact majeur sur le poids corporel, la perte de poids étant significativement améliorée dans le groupe aux probiotiques par rapport au groupe avec de la diète seule $(p=0,01)$. L'effet de l'administration de probiotiques alimentaires sur les profils glucidique et lipidique était faible (taille de l'effet (ES) 0,26 et 0,33, respectivement), mais meilleur que dans le groupe témoin, chez qui l'évolution était insignifiante (ES 0,10 et 0,10 , respectivement). D'un point de vue statistique, les différences étaient insignifiantes ( $p>0,05$ ).

Conclusions. Dans la gestion du profil métabolique des patients souffrant à la fois de SM et de T2DM, l'administration de probiotiques a eu des résultats bénéfiques, comme le soulignent les résultats de la présente étude.

Mots-clés: syndrome métabolique, diabète de type 2, poids, profil glucidique, profil lipidique.

this condition; increased triacylglycerols (>150 mg/ $\mathrm{dL}$ ) or specific therapy for this condition; increased fasting plasma glucose $>100 \mathrm{mg} / \mathrm{dL}$ or prediabetes; increased blood pressure (BP) (systolic $>130 \mathrm{mmHg}$ or diastolic $>85 \mathrm{mmHg}$ ) or specific treatment in patients already diagnosed with hypertension? ${ }^{7}$. Some studies present MS as a group of biochemical, metabolic and physiological risk factors usually connected to obesity, T2DM and cardiovascular disease ${ }^{8,9}$.

Previous published data have demonstrated the essential role of gut microbiota in influencing the functioning of gut metabolism like lipids, proteins and carbohydrates decomposition, energy and nutrients absorption and gut motility ${ }^{10,11}$. Recent research associates MS with particular disorders in gut microbiota $^{12-14}$. It was also suggested that probiotic intake has a positive impact on some clinical elements of $\mathrm{MS}^{14}$. The bacteria generating beneficial effects for animals and for humans are usually known as probiotics. Probiotics definition considers that they are live microorganisms which have effect on the host's health when they are consumed in proper quantity ${ }^{15}$. In animal models, probiotics were shown to decrease the blood glucose, ameliorating inflammation and prevent $\beta$-cell destruction ${ }^{16}$. Human clinical trials on various probiotics obtained mixed outcomes, some of them found no effect ${ }^{17}$, and other revealed a considerable glucose decreasing ${ }^{18}$. 
The objective of the StudY was to monitor the impact of probiotics in patients with T2DM and MS, regarding some of the clinical components of both disorders (weight status, body mass index (BMI), BP, glycemic and lipid profiles).

\section{Materials AND Methods}

A prospective 3-month comparative study was conducted between January - June 2020, in private medical offices of diabetes and nutritional diseases from Oradea, Romania, on 41 patients with T2DM and MS, of whom 19 patients were administered probiotics (study group) and 22 patients were not given probiotics (control group). Belonging to one group or another was decided by the patients' option to supplement with probiotics their treatment established by the diabetologist. According to the clinical characteristics and associated pathology, the allopathic therapy was individualized for each patient. The probiotic product used in this study is a spore-based supplement that contains Bacillus licheniformis, Bacillus indicus, Bacillus subtilis, Bacillus clausii, Bacillus coagulans, which produce antioxidants and thus manage to repair the imbalances of the intestinal flora. The administration was made according to the manufacturer's instructions (one capsule per day during the meal for 2 weeks, after which it was changed to 2 capsules per day for 3 months).

The patients' evaluation was performed at the beginning of the therapy and after 3 months. The evaluated parameters were as follows: lipid profile (total cholesterol, HDLc, low density lipoprotein cholesterol (LDLc), triglycerides), BP, glucose profile and weight status.

BP monitoring was carried out according to the 2018 European Society of Cardiology/ European Society of Hypertension Guidelines for the Management of Arterial Hypertension ${ }^{19}$. To evaluate the patients' weight status, the BMI $\left(\mathrm{kg} / \mathrm{m}^{2}\right)$ was used.

The blood samples were taken in the morning (after 12-14 hours of fasting) and were used to determine the levels of HDLc, LDLc and total cholesterols, triglycerides, glycosylated hemoglobin A1c (HbA1c) and basal blood glucose. The first four parameters afore-mentioned were determined using Beckman Coulter reagents with the Beckman Coulter AU680 analyzer (provided by Beckman Coulter Inc, Ireland). The analyses methods comprise enzymatic glycerol-3-phosphate oxidase method to determine triglycerides, the oxidase-peroxidase method to determine cholesterol, and colorimetric direct method to determine HDLc and LDLc. Hexokinase method was used to evaluate basal blood glucose, the selection of subjects being performed taking into account the fasting values. Plasmatic concentration of $<100 \mathrm{mg} /$ $\mathrm{dL}$ was regarded as normal value of basal blood glucose. HbAlc represents the accurate value of glucose over a period of 90-120 days prior to determination and was evaluated only for diabetic patients. Venous blood collected on ethylenediamine tetra-acetic acid anticoagulant was analyzed by - high-performance liquid chromatography (gold standard) using BioRad D-10 reagents and equipment.

Agreed by the Ethics Commission of the Clinical County Emergency Hospital, Oradea, Romania (no. 6398/08.03.2019), this research was performed according to WMA Ethical Declaration of Helsinki. Before being included in the study, each patient signed an informed consent form.

Statistical analysis was completed using EPIINFO, version 11, an Atlanta Centre of Disease Control and Prevention program adjusted to the medical statistics processing. The Student's method ( $t$ test) and $c^{2}$ tests were used to assess average parameter values like standard deviations, frequency ranges and statistical significance. Using assumptions that include numerical data, a test distribution similar to the normal one was performed. The paired t-test was used. Bravais-Pearson's correlation coefficient was applied to achieve a marker separated from the two variables measurement units. Statistical significance was established for a p-value of $<0.05$. The effect size (ES) was determined to assess the parameters change magnitude at different times. According to literature, the index decoding was systematized: small $\mathrm{ES}=0.20$, medium $\mathrm{ES}=0.50$, large $E S=0.80$. ES is essential to show the results of a quantitative study, as p-value identifies the effect, but does not show its magnitude.

\section{Results}

\section{Demographic data and clinical characteristics}

In the study group, men predominated (57.89\%), while women predominated $(59.09 \%)$ in the control group. There are no significant differences between the two groups in terms of sex distribution $(\mathrm{p}=0.284)$. Most patients in both groups were aged between 51-60 years (52.63\%, respectively $40.91 \%)$. The mean age was insignificantly higher in the study group compared to the control group (60.74 vs 58.14 years, $\mathrm{p}=0.348$ ). From the point of view of the origin environment, in the study group over $63 \%$ of patients came from the urban environment, and in the control group the urban/ rural ratio is $1: 1(p=0.403)$ (Table 1$)$.

Moreover, in the study group, insulin-dependent patients represented $63.16 \%$, an insignificantly higher percentage than in the control group (63.64\%) $(\mathrm{p}=0.975)$ (Figure 1). Complications of diabetes had a prevalence of $100.00 \%$ in the study group, slightly 
Table 1. Distribution by demographic characteristics

\begin{tabular}{|c|c|c|c|c|}
\hline \multirow{2}{*}{$\begin{array}{l}\text { Demographic } \\
\text { characteristics }\end{array}$} & \multicolumn{2}{|c|}{ Study group } & \multicolumn{2}{|c|}{ Control group } \\
\hline & No. & $\%$ & No. & $\%$ \\
\hline \multicolumn{5}{|c|}{ Gender } \\
\hline Male & 11 & 57.89 & 9 & 40.91 \\
\hline Female & 8 & 42.11 & 13 & 59.09 \\
\hline Total & 19 & 100.00 & 22 & 100.00 \\
\hline \multicolumn{5}{|c|}{ Age (years) } \\
\hline & 1 & 5.26 & 5 & 22.73 \\
\hline & 10 & 52.63 & 9 & 40.91 \\
\hline & 7 & 36.84 & 5 & 22.73 \\
\hline & 1 & 5.26 & 3 & 13.64 \\
\hline Min-Max & \multicolumn{2}{|c|}{$48-76$} & \multicolumn{2}{|c|}{$43-72$} \\
\hline Average age & \multicolumn{2}{|c|}{$60.74 \pm 5.84$} & \multicolumn{2}{|c|}{$58.14 \pm 11.17$} \\
\hline \multicolumn{5}{|c|}{ Environment } \\
\hline Rural & 7 & 36.84 & 11 & 50.00 \\
\hline Urban & 12 & 63.16 & 11 & 50.00 \\
\hline
\end{tabular}

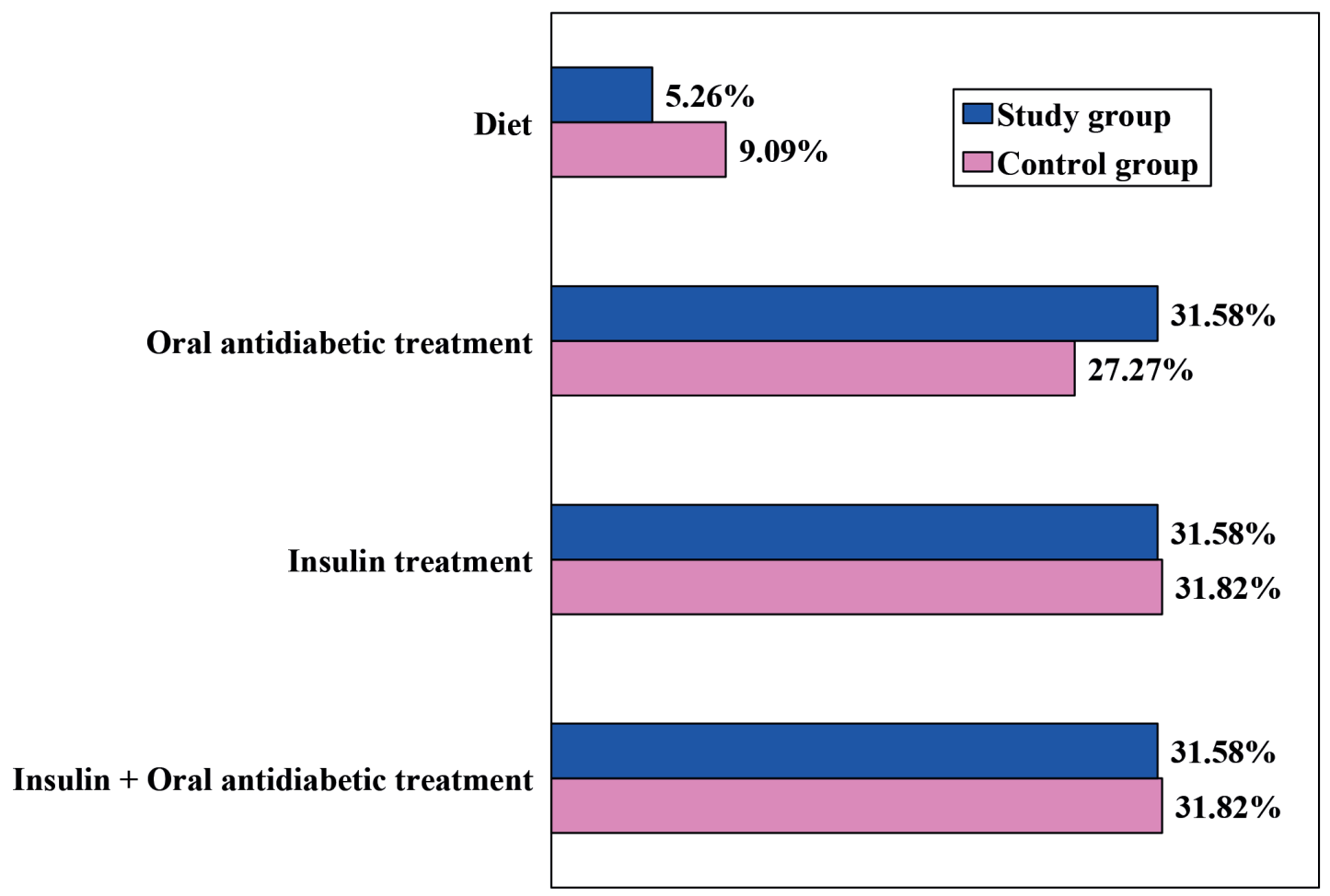

Figure 1. Distribution by antidiabetic treatment

higher than in the control group (81.82\%) ( $\mathrm{p}=0.053)$. In both groups the most frequent complication was kidney disease (73.68 vs $40.91 \%$, $\mathrm{p}=0.037)$, stages 3-4 having an insignificantly higher prevalence in the control group (27.27 vs $15.79 \%, p=0.382)$. Both polyneuropathy and retinopathy were more common in the study group, but without significant differences $(61.70$ vs $45.28 \%, p=0.102$, respectively 14.89 vs $9.43 \%, p=0.404)($ Table 2).
In both groups, most cases with MS met all 5 criteria ( 47.37 vs. $54.55 \%, p=0.651$ ) (Figure 2). Obesity had a prevalence of $94.74 \%$ in the study group, insignificantly lower than in the control group $(95.45 \%, p=0.917)$. The mean value of BMI was $34.17 \mathrm{~kg} / \mathrm{m}^{2}$ in the study group, insignificantly lower than in the control group $\left(35.51 \mathrm{~kg} / \mathrm{m}^{2}, \mathrm{p}=0.337\right)$ (Table 2). Also, the associated diseases were identified in all patients, the most common being heart 
Table 2. Distribution by complications of diabetes and weight status

\begin{tabular}{|c|c|c|c|c|}
\hline \multirow{2}{*}{ Complications } & \multicolumn{2}{|c|}{ Study group } & \multicolumn{2}{|c|}{ Control group } \\
\hline & No. & $\%$ & No. & $\%$ \\
\hline \multicolumn{5}{|c|}{ Diabetes } \\
\hline With complications & 19 & 100.00 & 18 & 81.82 \\
\hline Diabetic polyneuropathy & 16 & 84.21 & 12 & 54.55 \\
\hline Diabetic retinopathy & 3 & 15.79 & 3 & 13.64 \\
\hline Chronic kidney disease & 17 & 89.47 & 15 & 68.18 \\
\hline Stage 1 & 0 & 0.00 & 0 & 0.00 \\
\hline Stage 2 & 14 & 73.68 & 9 & 40.91 \\
\hline Stage 3 & 2 & 10.53 & 6 & 27.27 \\
\hline Stage 4 & 1 & 5.26 & 0 & 0.00 \\
\hline \multicolumn{5}{|c|}{ Weight status } \\
\hline Normal weight & 0 & 0.00 & 0 & 0.00 \\
\hline Overweight & 1 & 5.26 & 1 & 4.55 \\
\hline Obesity & 18 & 94.74 & 21 & 95.45 \\
\hline Obese grade 1 & 13 & 68.42 & 10 & 45.45 \\
\hline Obese grade 2 & 3 & 15.79 & 8 & 36.36 \\
\hline Obese grade 3 & 2 & 10.53 & 3 & 13.64 \\
\hline $\operatorname{Min} / \operatorname{Max}$ & \multicolumn{2}{|c|}{$29.75 / 41.66$} & \multicolumn{2}{|c|}{$25.15 / 50.39$} \\
\hline Average BMI $\left(\mathrm{kg} / \mathrm{m}^{2}\right)$ & \multicolumn{2}{|c|}{$34.17 \pm 3.58$} & \multicolumn{2}{|c|}{$35.51 \pm 5.22$} \\
\hline
\end{tabular}

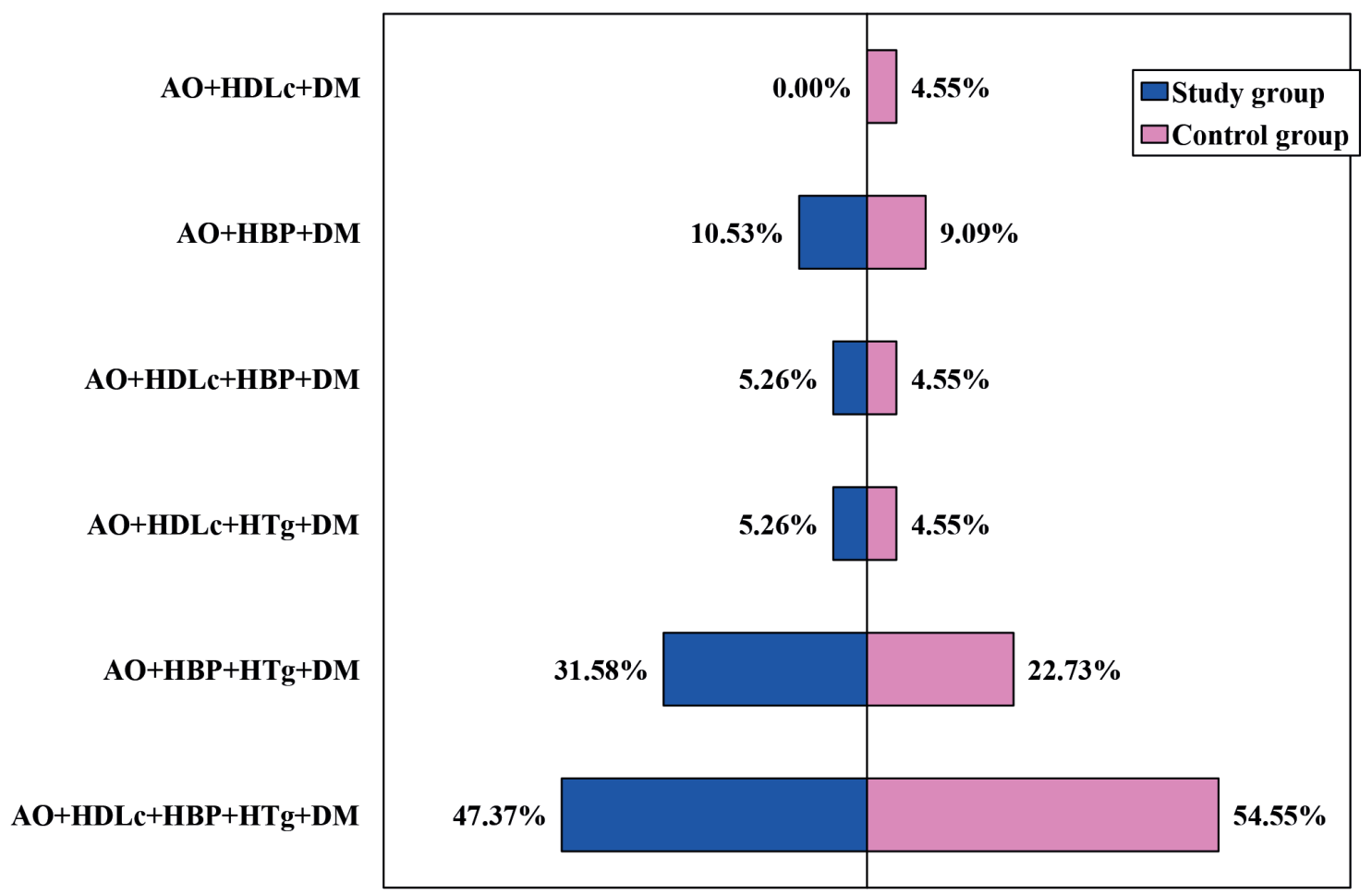

Figure 2. MS criteria

disease (94.74 vs. $95.45 \%, p=0.917)$, liver disease (73.68 vs. $86.36 \%, p=0.313)$ and dyslipidemia $(57.89$ vs $81.82 \%, p=0.097$ ) (Table 3 ). The history of major events was registered in $15.79 \%$ of the patients of the study group and in $9.09 \%$ of the patients of the control group $(\mathrm{p}=0.518)$ (Figure 3$)$. The most used drugs in both groups were diuretics (63.16 vs $54.55 \%$, $\mathrm{p}=0.582$ ), beta-blockers and statins (36.84 vs $22.73 \%$, $\mathrm{p}=0.328)$, and calcium channel blockers (31.58 vs. 22.73\%, p=0.529) (Table 3). 


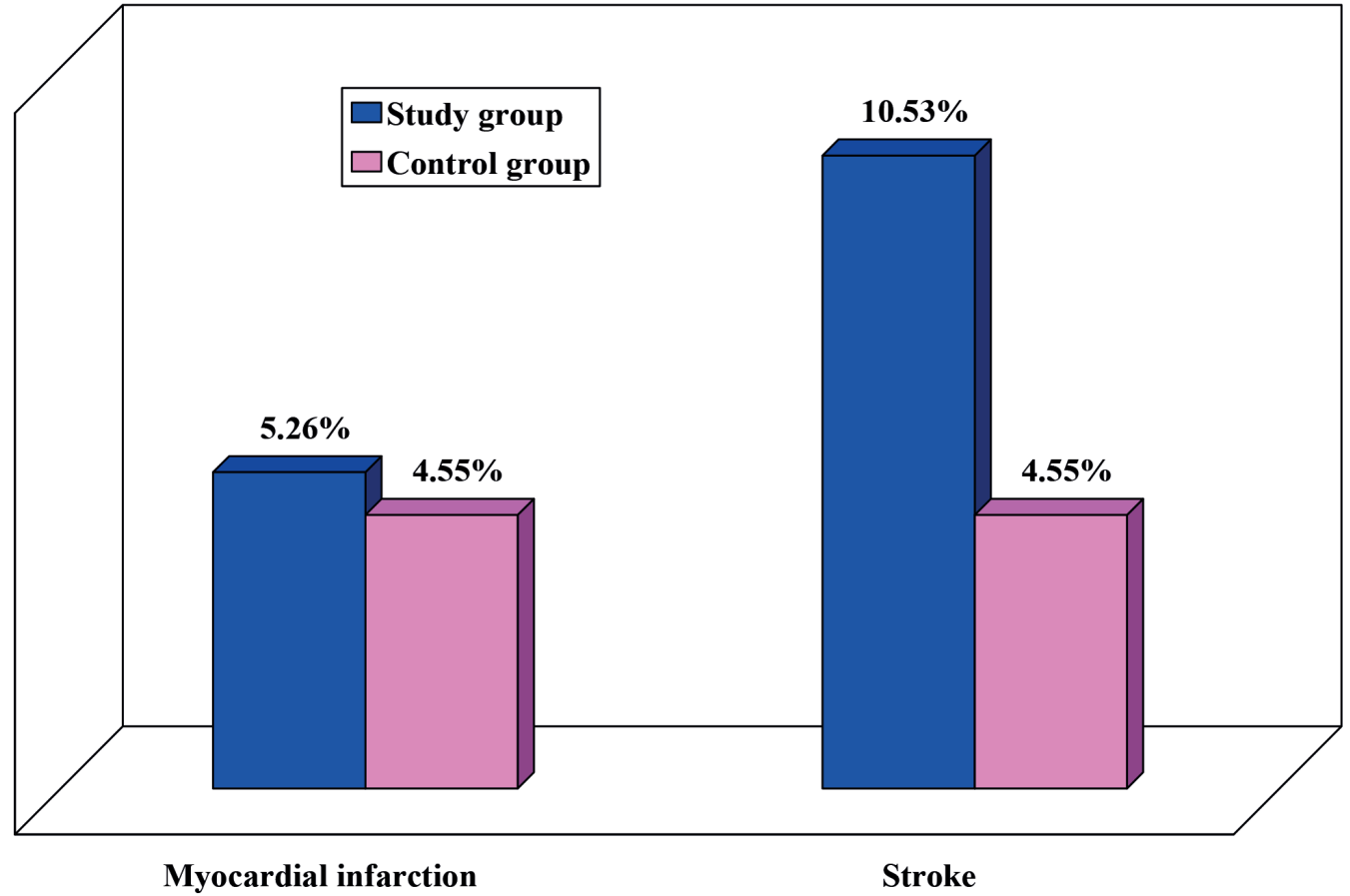

Figure 3. Distribution by major events

Table 3. Distribution by associated diseases and treatment

\begin{tabular}{|c|c|c|c|c|}
\hline \multirow{2}{*}{ Associated diseases } & \multicolumn{2}{|c|}{ Study group } & \multicolumn{2}{|c|}{ Control group } \\
\hline & No. & $\%$ & No. & $\%$ \\
\hline Total & 19 & 100.00 & 22 & 100.00 \\
\hline Heart diseases & 18 & 94.74 & 21 & 95.45 \\
\hline Hypertension & 18 & 94.74 & 21 & 95.45 \\
\hline Ischemic heart disease & 14 & 73.68 & 12 & 54.55 \\
\hline Heart failure & 5 & 26.32 & 3 & 13.64 \\
\hline Dyslipidemia & 11 & 57.89 & 18 & 81.82 \\
\hline Liver disease & 14 & 73.68 & 19 & 86.36 \\
\hline Lung disease & 3 & 15.79 & 1 & 4.55 \\
\hline Thyroid damage & 3 & 15.79 & 1 & 4.55 \\
\hline Depression & 1 & 5.26 & 2 & 9.09 \\
\hline Other comorbidities & 8 & 17.02 & 7 & 13.21 \\
\hline \multicolumn{5}{|c|}{ Treatment } \\
\hline Angiotensin receptor blocker & 4 & 21.05 & 3 & 13.64 \\
\hline Calcium channels blocker & 6 & 31.58 & 5 & 22.73 \\
\hline Beta blocker & 7 & 36.84 & 4 & 18.18 \\
\hline Diuretic & 12 & 63.16 & 12 & 54.55 \\
\hline Statin & 7 & 36.84 & 5 & 22.73 \\
\hline Fibrate & 4 & 21.05 & 3 & 13.64 \\
\hline Antiplatelet drug & 2 & 10.53 & 5 & 22.73 \\
\hline
\end{tabular}

\section{Evolution at 3 months}

The mean BMI values decreased insignificantly in both groups (from 34.17 to $33.43 \mathrm{~kg} / \mathrm{m}^{2}, \mathrm{p}=0.519$, respectively from 35.51 to $35.07 \mathrm{~kg} / \mathrm{m}^{2}, \mathrm{p}=0.786$ ). Compared to the control group, the BMI value was insignificantly lower in the study group, both at the initial and at the final evaluation (34.17 vs 35.51 $\mathrm{kg} / \mathrm{m}^{2}, \mathrm{p}=0.337$, respectively $\left(33.43\right.$ vs $35.07 \mathrm{~kg} / \mathrm{m}^{2}$, $\mathrm{p}=0.244)$. The effect of dietary probiotic administration on BMI was small in the study group (ES=0.21) and insignificant in the control group $(E S=0.08)$ (Figure 4). 
Dietary follow-up and/ or probiotic administration resulted in weight loss in $73.68 \%$ of patients in the study group and in $68.18 \%$ of patients in the control group. The weight loss was significantly higher in the study group compared to the control group (2.05 vs $1.18 \mathrm{~kg}, \mathrm{p}=0.011$ ) (Table 4).

The mean values of systolic/diastolic BP decreased insignificantly, both in the study group (from 140.21 to $137.42 \mathrm{mmHg}, \mathrm{p}=0.618$, respectively from
85.32 to $84.42 \mathrm{mmHg}, \mathrm{p}=0.861$ ), and in the control group (from 142.23 to $140.45 \mathrm{mmHg}, \mathrm{p}=0.752$, respectively from 84.95 to $84.50 \mathrm{mmHg}, \mathrm{p}=0.866$ ). At both evaluations, initial and at 3 months, there were no significant differences between the two groups, in terms of both BP (systolic and diastolic); moreover, the effect on systolic and diastolic BP was insignificant $(\mathrm{ES}=0.16$ vs $\mathrm{ES}=0.09$, respectively $\mathrm{ES}=0.06$ vs $\mathrm{ES}=0.04)$ (Figure 5).

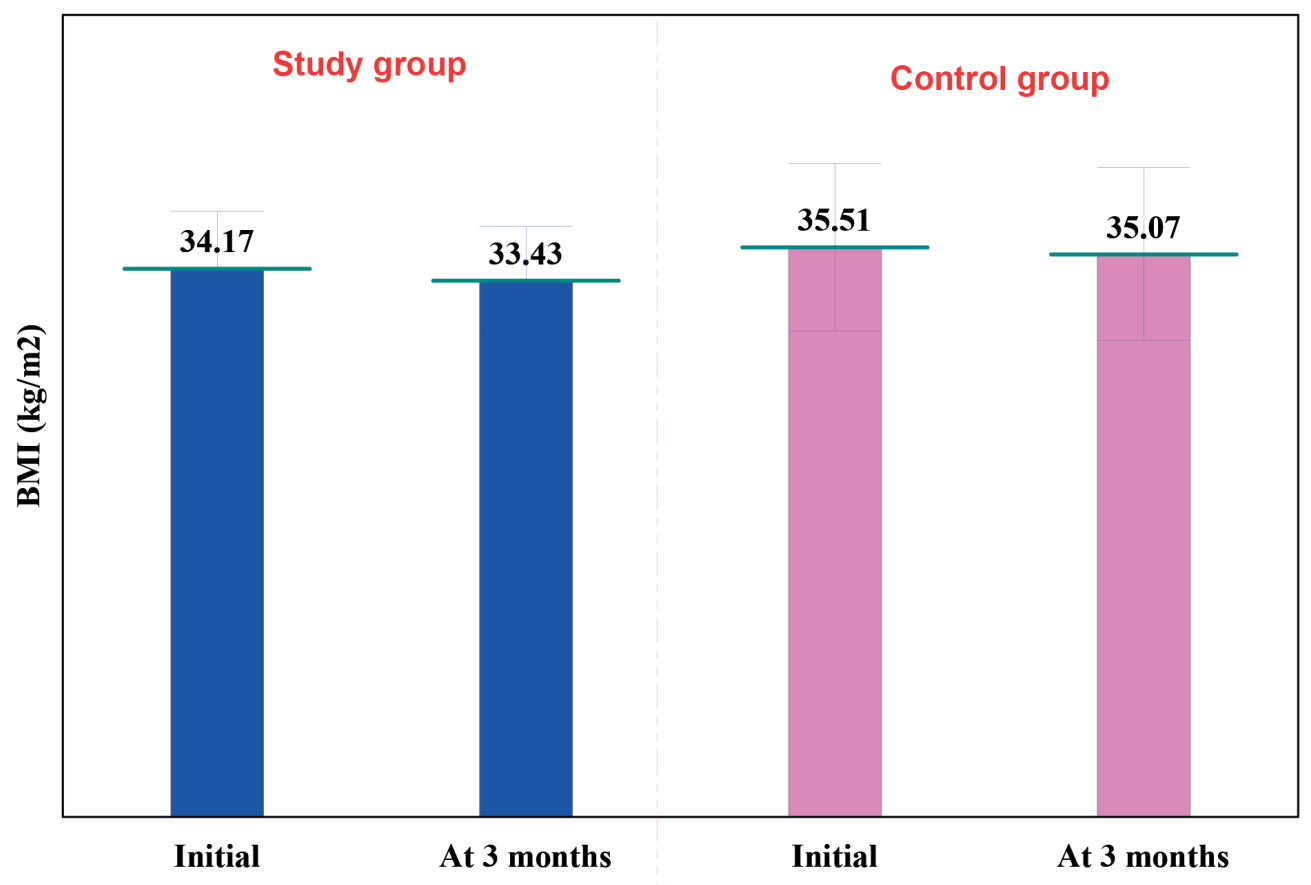

Figure 4. BMI evolution

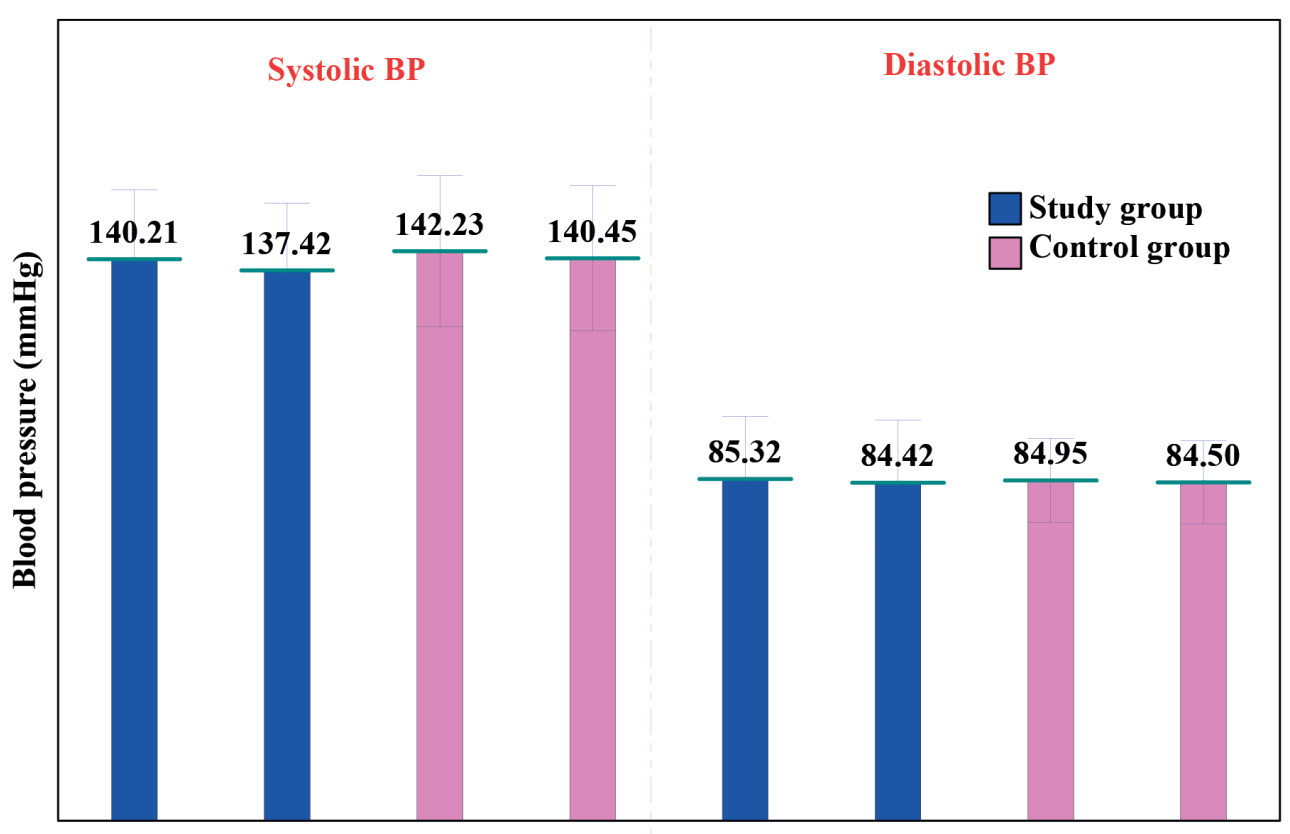

Initial At 3 months Initial At 3 months Initial At 3 months Initial At 3 months

Figure 5. Blood pressure evolution 
Table 4. Evolution of body weight $(\mathrm{p}=0.11)$

\begin{tabular}{ccccc}
\hline \multirow{2}{*}{ Weight status } & \multicolumn{2}{c}{ Study group } & \multicolumn{2}{c}{ Control group } \\
\cline { 2 - 5 } & No. & $\%$ & No. & \% \\
\hline Increased weight & 3 & 15.79 & 5 & 22.73 \\
\hline Unchanged weight & 2 & 10.53 & 2 & 9.09 \\
\hline Decreased weight & 14 & 73.68 & 15 & 68.18 \\
\hline Weight loss at 3 months & \multicolumn{2}{c}{$2.05 \pm 1.06$} & $1.18 \pm 1.02$ \\
\hline
\end{tabular}

Mean blood glucose values decreased insignificantly in both groups (from 143.21 to $135.32 \mathrm{mg} / \mathrm{dL}$, $\mathrm{p}=0.414$, respectively from 148.36 to $145.32 \mathrm{mg} / \mathrm{dL}$, $\mathrm{p}=0.706$ ). In both evaluations the mean blood glucose value was insignificantly lower in the study group
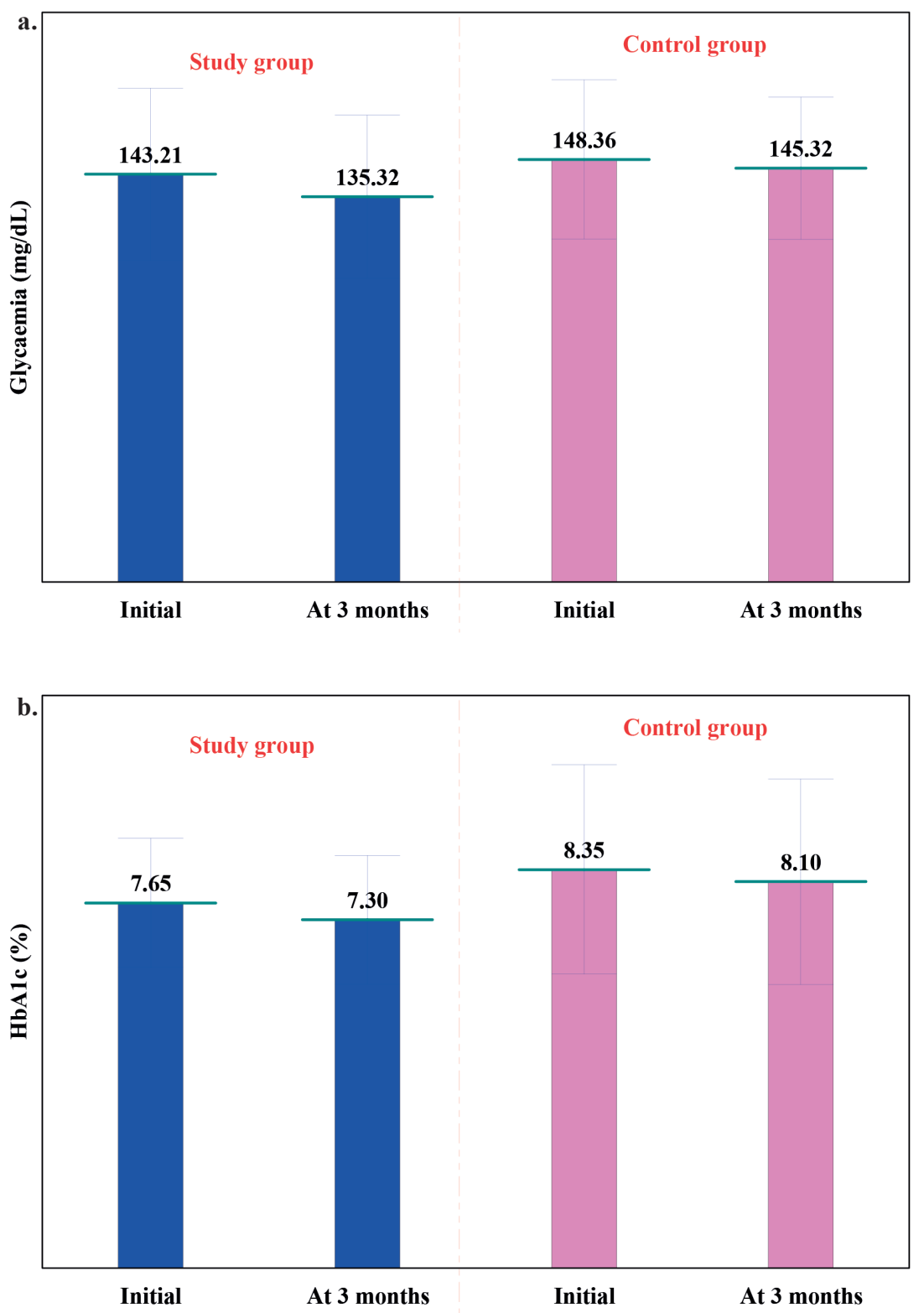

Figure 6. a. Glycaemia and b. HbA1c evolution compared to the control group (143.21 vs $148.36 \mathrm{mg} /$ $\mathrm{dL}, \mathrm{p}=0.577$ and 135.32 vs $145 \mathrm{mg} / \mathrm{dL}, \mathrm{p}=0.245)$. The effect of dietary probiotic administration on blood glucose was small in the study group $(E S=0.26)$ and insignificant in the control group $(E S=0.10)$. The mean values of HbAlc decreased insignificantly in both groups (from 7.65 to $7.30 \%, p=0.428$, respectively from 8.35 to 8.10 $\%, p=0.695)$. In both evaluations, the mean value of $\mathrm{HbAlc}$ was insignificantly lower in the study group compared to the control group (7.65 vs $8.35 \%$, $\mathrm{p}=0.220$, respectively $7.30 \mathrm{vs}$ $8.10 \%, p=0.160)$. The effect of dietary probiotic administration on HbA1c was small in the study group $(E S=0.26)$ and insignificant in the control group (ES=0.12) (Figure 6).

The mean cholesterol values decreased insignificantly in both groups (from 176.79 to $165.47 \mathrm{mg} / \mathrm{dL}, \mathrm{p}=0.309$, respectively from 183.18 to $179.09 \mathrm{mg} / \mathrm{dL}, \mathrm{p}=0.753)$, being insignificantly lower in the study group compared to the control group, in both evaluations (176.79 vs $183.18 \mathrm{mg} / \mathrm{dL}$, $\mathrm{p}=0.600$, respectively 165.47 vs $179.09 \mathrm{mg} / \mathrm{dL}, \mathrm{p}=0.258$ ). The effect of dietary probiotic administration on cholesterol was small in the study group $(E S=0.33)$ and insignificant in the control group ( $E S=0.10)$. Mean LDLc values decreased insignificantly in both groups (from 105.00 to $99.26 \mathrm{mg} / \mathrm{dL}$, $\mathrm{p}=0.563$, and from 117.86 to $111.23 \mathrm{mg} / \mathrm{dL}$ respectively, $\mathrm{p}=0.476$ ). In both evaluations, the mean LDLc value was 


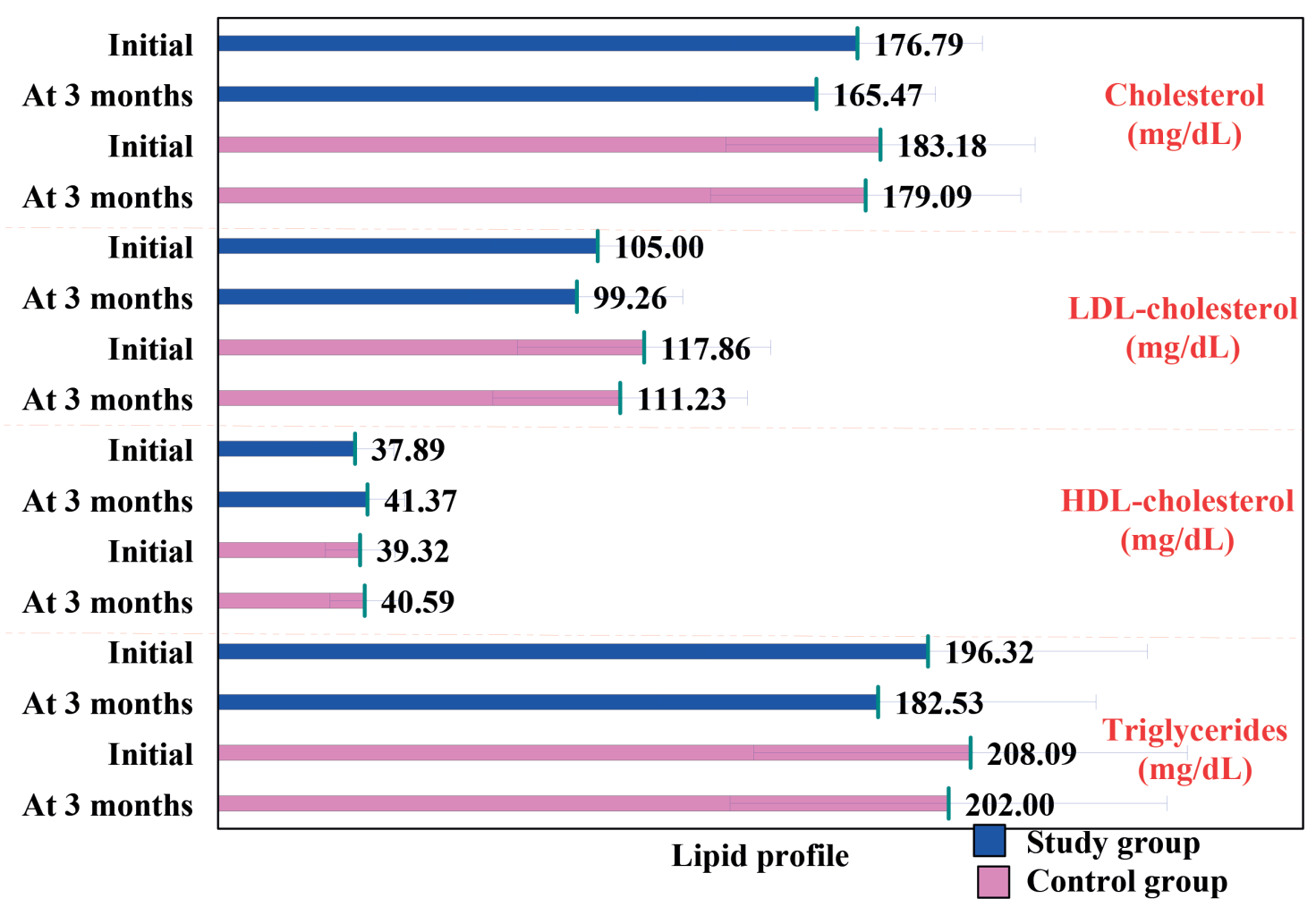

Figure 7. Lipid profile evolution

insignificantly lower in the study group compared to the control group (105.00 vs $117.86 \mathrm{mg} / \mathrm{dL}, \mathrm{p}=0.160$, respectively 99.26 vs $111.23 \mathrm{mg} / \mathrm{dL}, \mathrm{p}=0.242$ ). The effect of dietary probiotic administration on LDLc was small in the study group (ES=0.20) and insignificant in the control group (ES=0.19). The mean values of HDLc increased insignificantly in both groups (from 37.89 to $41.37 \mathrm{mg} / \mathrm{dL}, \mathrm{p}=0.316$, respectively from 39.32 to $40.59 \mathrm{mg} / \mathrm{dL}, \mathrm{p}=0.663)$. At the initial evaluation, the mean value of HDLc was insignificantly lower in the study group compared to the control group (37.89 vs $39.32 \mathrm{mg} / \mathrm{dL}, \mathrm{p}=0.660$ ), and at the evaluation at 3 months it was insignificantly higher (41.37 vs $40.59 \mathrm{mg} / \mathrm{dL}, \mathrm{p}=0.805)$. The effect of dietary probiotic administration on HDLc was small in the study group (ES=0.32) and insignificant in the control group (ES=0.13). Mean triglyceride values decreased insignificantly in both groups (from 196.32 to $182.53 \mathrm{mg} / \mathrm{dL}, \mathrm{p}=0.487$, respectively from 208.09 to $202.00 \mathrm{mg} / \mathrm{dL}, \mathrm{p}=0.739$ ).

In both evaluations, the mean triglyceride value was insignificantly lower in the study group than in the control group (196.32 vs $208.09 \mathrm{mg} / \mathrm{dL}, \mathrm{p}=0.537$, respectively 182.53 vs $202.00 \mathrm{mg} / \mathrm{dL}, \mathrm{p}=0.309)$. The effect of dietary probiotic administration on triglycerides was small in the study group (ES=0.23) and insignificant in the control group $(\mathrm{ES}=0.10)$ (Figure 7).

\section{Discussion}

MS has a multifactorial etiology, with diverse associations between factors such as genetic predisposition, behaviours, diet and environment. Physiological risk factors (including excessive adipose tissue, lipo-toxicity, increased cortisol, systemic inflammation, increased oxidative stress) are linked to pathogenesis and production of metabolic disorders (i.e. T2DM, dyslipidemia, hypertension, non-alcoholic fatty liver disease, etc) ${ }^{20}$. These scenarios also result in MS pathophysiology, increasing the risk of CVDs ${ }^{21}$.

Increasing evidence underlines the gut dysbiosis impact on the pathogenesis of metabolic disorders like MS, T2DM and obesity. Studies highlighted the connection between gut microbiome diversity and richness decrease and increased risk for developing insulin resistance-based illnesses in obese subjects, therefore gut microbiome became important in improving metabolic disorders determined by lifestyle ${ }^{22,23}$. Clinical results sustain the idea that improving gut microbiota with probiotics is efficient in preventing and managing diabetes, having favorable influence on the T2DM patients' metabolic control ${ }^{23,24}$.

Probiotics administered orally were demonstrated to lower serum glucose levels and improve lipid metabolism in animal models ${ }^{25}$. The probiotics 
action on serum glucose and lipid profiles in human patients were also studied but with inconsistent findings $^{26}$. The differences may result from the use of various probiotic strains. Multispecies probiotics seem to be more efficient on metabolic disorders ${ }^{27}$.

Probiotics intake in MS patients have shown improvements in their BMI, BP, lipid profile and glucose metabolism, as Tenorio-Jiménez et al. mentioned in their meta-analysis. Although there is a diversity of results obtained in the published data that were studied, the administration of probiotics to patients with MS improves some clinical parameters, leading to a decrease in the inflammatory biomarkers (interleukin-6, soluble vascular cell adhesion molecule 1, vascular endothelial growth factor, tumour necrosis factor- $\alpha$, and thrombomodulin ${ }^{28}$.

Significant decrease of at least one of the components generally determines reversal of the $\mathrm{MS}^{29}$. In the present study, the administration of dietary probiotics to diabetic patients had a major impact on body weight, with weight loss being significantly greater in the probiotic group than in the diet-only group. The effect of dietary probiotic administration on blood glucose and $\mathrm{HbA1c}$ was small $(\mathrm{ES}=0.26)$ but better than in the control group ( $E S=0.10$ ). The effect of probiotics on glucose metabolism in various mice models and suitable human epithelial cell lines was assessed by several studies ${ }^{30,31}$ all highlighting a decrease in fasting or postprandial glucose and HbAlc after probiotics intake. Probiotic yogurt intake was demonstrated to considerably enhance glucose metabolism in some studies on probiotics, while other studies did not present any improvements ${ }^{14,32}$.

The main risk factors for CVDs are increased BP, T2DM and increased levels of total cholesterol ${ }^{33}$. To decrease the risk of severe cardiovascular events it is important to lower the LDLc/ total cholesterol increased values ${ }^{34}$. The risk of cardiovascular illnesses increases by $20 \%$ in women and $24 \%$ in men, with every $1 \mathrm{mmol} / \mathrm{L}$ increase in total cholesterol levels ${ }^{5}$. In this study, the effect of dietary probiotic administration on cholesterol was small in the study group $(E S=0.33)$ and insignificant in the control group $(E S=0.10)$. Positive changes of various parameters determine a decrease in the intensity of complications generated by T2DM, and implicitly lower mortality, though the reduced changes are not clinically significant.

The severity of some MS components was decreased in the period when probiotics were administered. Though the differences in the components' values were not statistically significant, using greater number of subjects the significance may increase.

The small number of patients and the short period of patients' monitoring are the main limitations of this study, which presents intermediate results of a complex ongoing research that evaluates the effects of manipulating the intestinal microbiome with probiotics in patients with T2DM and MS. Nevertheless, further research is needed to demonstrate whether probiotics can be used as prevention or therapeutic agents in patients with MS or diabetes.

\section{Conclusions}

According to the results of this study, the probiotics intake is efficient in managing the metabolic profile in patients with SM and T2DM. Data analysis indicated a significant effect only on body weight. The response to treatment of both systolic and diastolic blood pressure values, cholesterol, triglyceride, HDLc, LDLc levels, HbA1c and serum glucose values was better in the probiotics group, the differences being insignificant in the control group. The associated effects of various antidiabetic treatments and probiotic strains need further investigation.

\section{Authors Contribution:}

Conceptualization, R.A.C.A., D.M.T., C.M.V. and S.B.; methodology, D.M.T., A.L.P. and S.B.; software, R.A.C.A., T.C.G., D.M.T. and S.B.; validation, D.M.T and S.B..; formal analysis, R.A.C.A., T.C.G., A.A., G.A. and S.B.; investigation, R.A.C.A., T.C.G., D.M.T and S.B.; resources, R.A.C.A., A.A and G.A..; data curation, R.A.C.A; writing-original draft preparation, R.A.C.A., D.M.T., A.L.P, C.M.V. and S.B.; writing-review and editing, R.A.C.A., D.M.T., A.L.P, C.M.V. and S.B.; visualization, S.B.; supervision, S.B.; project administration, S.B. All authors have read and agreed with the final version of this article.

\section{Compliance with Ethics Requirements:}

"The authors declare no conflict of interest regarding this article"

"The authors declare that all the procedures and experiments of this study respect the ethical standards in the Helsinki Declaration of 1975, as revised in 2008(5), as well as the national law. Informed consent was obtained from all the patients included in the study"

"No funding for this study"

\section{Acknowledgements: \\ None}

\section{References}

1. GBD 2015 Obesity Collaborators. Health effects of overweight and obesity in 195 countries over 25 years. The New England Journal of Medicine. 2017;377:13-27. 
2. Bray G, Kim K, Wilding J, Federation WO. Obesity: a chronic relapsing progressive disease process. A position statement of the World Obesity Federation. Obesity Reviews. 2017;18:715-23.

3. Kalofoutis C, Piperi C, Kalofoutis A, Harris F, Phoenix D, Singh J. Type II diabetes mellitus and cardiovascular risk factors: Current therapeutic approaches. Experimental $\mathbb{E}$ Clinical Cardiology. 2007;12(1):17-28.

4. Ogurtsova K, da Rocha Fernandes JD, Huang Y, et al. IDF Diabetes Atlas: Global estimates for the prevalence of diabetes for 2015 and 2040. Diabetes Research and Clinical Practice. 2017;128:40-50

5. NCD Risk Factor Collaboration (NCD-RisC). Worldwide trends in body-mass index, underweight, overweight, and obesity from 1975 to 2016: a pooled analysis of 2416 population-based measurement studies in 128.9 million children, adolescents, and adults. Lancet (London, England). 2017; 390(10113):2627-2642.

6. Alberti KG, Eckel RH, Grundy SM, Zimmet PZ, Cleeman JI, Donato KA. International Diabetes Federation Task Force on Epidemiology and Prevention. National Heart, Lung, and Blood Institute. American Heart Association. World Heart Federation et al. Harmonizing the metabolic syndrome: A joint interim statement of the International Diabetes Federation Task Force on Epidemiology and Prevention; National Heart, Lung, and Blood Institute. Circulation. 2009;120:1640-1645.

7. Alberti KG, Zimmet P, Shaw J. Metabolic syndrome A new world-wide definition. A consensus statement from the international diabetes federation. Diabetic Medicine. 2006;23:469-480.

8. Kaur J. A comprehensive review on metabolic syndrome. Cardiology Research and Practice. 2014;2014:943162.

9. Reasner CA. Reducing cardiovascular complications of type 2 diabetes by targeting multiple risk factors. Journal of Cardiovascular Pharmacology and Therapeutics. 2008;52(2):136-44

10. Wu HJ, Wu E. The role of gut microbiota in immune homeostasis and autoimmunity. Gut Microbes. 2012;3(1):4-14.

11. Arora A, Behl T, Sehgal A, et al. Unravelling the involvement of gut microbiota in type 2 diabetes mellitus. Life Sciences. 2021; 273, 119311.

12. Tilg H, Moschen AR. Food, immunity, and the microbiome. Gastroenterology. 2015;148(6): 1107-19.

13. Sáez-Lara MJ, Robles-Sanchez C, Ruiz-Ojeda FJ, Plaza-Diaz J, Gil A. Effects of probiotics and synbiotics on obesity, insulin resistance syndrome, type 2 diabetes and non-alcoholic fatty liver disease: a review of human clinical trials. International Journal of Molecular Sciences. 2016;17:928.

14. Corb Aron RA, Abid A, Vesa CM, et al. Recognizing the benefits of pre-/probiotics in metabolic syndrome and type 2 diabetes mellitus considering the influence of Akkermansia muciniphila as a key gut bacterium. Microorganisms. 2021;9(3):618.

15. Al-Salami H, Butt G, Fawcett JP, Tucker IG, Golocorbin-Kon S, Mikov M. Probiotic treatment reduces blood glucose levels and increases systemic absorption of gliclazide in diabetic rats. European Journal of Drug Metabolism and Pharmacokinetic s. $2008 ; 33$ (2):101-106.

16. Mazloom Z, Yousefinejad A, Dabbaghmanesh MH. Effect of probiotics on lipid profile, glycemic control, insulin action, oxidative stress, and inflammatory markers in patients with type 2 diabetes: a clinical trial. Iranian Journal of Medical Sciences. 2013;38 (1):38-43.
17. Ejtahed HS, Mohtadi-Nia J, Homayouni-Rad A, Niafar M, Asghari-Jafarabadi M, Mofid V. Probiotic yogurt improves antioxidant status in type 2 diabetic patients. Nutrition. 2012;28 (5):539-543.

18. Burdge C, Lillycrop KA, Phillips ES, Slater-Jefferies JL, Jackson AA, Hanson MA. Folic acid supplementation during the juvenile-pubertal period in rats modifies the phenotype and epigenotype induced by prenatal nutrition. Journal of Nutrition. 2009;139:1054-1060,

19. Williams B, Mancia G, Spiering W, et al. 2018 ESC/ESH Guidelines for the management of arterial hypertension: The Task Force for the management of arterial hypertension of the European Society of Cardiology (ESC) and the European Society of Hypertension (ESH), European Heart Journal. 2018;39(33):3021-3104.

20. Epingeac ME, Gaman MA, Diaconu C, Gad M, Gaman AM. The evaluation of oxidative stress in obesity. Rev Chim (Bucharest) 2019;70(6):2241-2244.

21. Vesa CM, Popa L, Popa AR, et al. Current data regarding the relationship between type 2 diabetes mellitus and cardiovascular risk factors. Diagnostics. 2020;10(5):314.

22. Lye HS, Kuan CY, Ewe JA, Fung WY, Liong MT. The improvement of hypertension by probiotics: effects on cholesterol, diabetes, renin, and phytoestrogens. International Journal of Molecular Sciences. 2009;10:3755-3775.

23. Kocsis T, Molnár B, Németh D, et al. Probiotics have beneficial metabolic effects in patients with type 2 diabetes mellitus: a meta-analysis of randomized clinical trials. Scientific Reports. 2020;10:11787.

24. Rad A, Abbasalizadeh S, Vazifekhah S, et al. The future of diabetes management by healthy probiotic microorganisms. Current Diabetes Reviews. 2017;13(6):582-589.

25. Kassaian N, Feizi A, Aminorroaya A, Amini M. Probiotic and symbiotic supplementation could improve metabolic syndrome in prediabetic adults: A randomized controlled trial. Diabetes ËMetabolic Syndrome. 2019;13(5):2991-2996.

26. Sayin SI, Wahlström A, Felin J, et al. Gut microbiota regulates bile acid metabolism by reducing the levels of tauro-beta-muricholic acid, a naturally occurring FXR antagonist. Cell Metabolism. 2013;17 (2):225-235.

27. Ilanne-Parikka P, Eriksson JG, Lindström J, et al. Prevalence of the metabolic syndrome and its components: findings from a Finnish general population sample and the Diabetes Prevention Study cohort. Diabetes Care. 2004;27 (9):2135-2140.

28. Tenorio-Jiménez C, Martinez-Ramirez MJ, Gil A, Gomez-Llorente C. Effects of probiotics on metabolic syndrome: a systematic review of randomized clinical trials. Nutrients. 2020;12(1):124.

29. Lin CH, Lin CC, Shibu MA, et al. Oral Lactobacillus reuteri GMN-32 treatment reduces blood glucose concentrations and promotes cardiac function in rats with streptozotocin-induced diabetes mellitus. British Journal of Nutrition. 2014;111(4):598-605.

30. Al-Salami H, Butt G, Tucker I, Mikov M. Influence of the semisynthetic bile acid MKC on the ileal permeation of gliclazide in vitro in healthy and diabetic rats treated with probiotics Methods and Findings in Experimental and Clinical Pharmacology. 2008;30(2):107-113.

31. Ejtahed HS, Mohtadi-Nia J, Homayouni-Rad A, Niafar M, Asghari-Jafarabadi M, Mofid V. Probiotic yogurt improves antioxidant status in type 2 diabetic patients. Nutrition. 2012;28(5):539-43 
32. Collaboration APCS. Cholesterol, diabetes and major cardiovascular diseases in the Asia-Pacific region. Diabetologia. 2007;50:2289-2297.

33. Gaman MA, Cozma MA, Dobrica EC, Bacalbasa N, Bratu OG, Diaconu CC. Dyslipidemia: a trigger for coronary heart disease in Romanian patients with diabetes. Metabolites 2020;10(5),195.

34. Peters SA, Singhateh Y, Mackay D, Huxley RR, Woodward $\mathrm{M}$. Total cholesterol as a risk factor for coronary heart disease and stroke in women compared with men: a systematic review and meta-analysis. Atherosclerosis. 2016;248:123-131. 